Research Article

\title{
EFFECT OF TOTAL MIXED RATION BASED COMPLETE PELLET FEED ON THE PERFORMANCES OF STALL FED NATIVE SHEEP
}

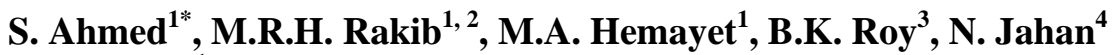 \\ ${ }^{1}$ Goat and Sheep Production Research Division \\ Bangladesh Livestock Research Institute, Savar, Dhaka, Bangladesh. \\ ${ }^{2}$ Department of Clinical Veterinary Medicine, College of Veterinary Medicine \\ China Agricultural University, Beijing, China. \\ ${ }^{3}$ Animal Production Research Division, Bangladesh Livestock Research Institute \\ Savar, Dhaka, Bangladesh. \\ ${ }^{4}$ Animal Biotechnology Division, National Institute of Biotechnology \\ Ganakbari, Ashulia, Savar, Dhaka, Bangladesh.
}

\begin{abstract}
A complete pellet feed was developed using $40 \%$ roughage (Rice straw) and $60 \%$ concentrate (Rice polish $50 \%$, Maize crush $16 \%$, Soybean meal $20 \%$, Molasses $10 \%$, Salt $2 \%$, DCP $1 \%$, Vitaminmineral premix $0.5 \%$, Pellet binder $0.5 \%$ ) for commercial sheep production under stall feeding system. To know the effect of complete pellet feed on animal performances, both on-station and on-farm trials were conducted in growing sheep. The results of the experiment demonstrated that in the traditional system of rearing; only $22.42 \mathrm{~g}$ daily weight gain was observed. While, feeding of complete pellet feed achieved $84.98 \mathrm{~g}$, and $100.67 \mathrm{~g}$ daily weight gain at on-farm and on-station condition respectively suggesting that pelleting enhanced the efficiency of utilization of feed. However, no differences were observed for the feed cost per kg weight gain, feed conversion ratio (FCR) and benefit-cost ratio (BCR) among the pellet feeding group and other group. But results suggest that complete pellet feed would be more economical for commercial sheep production under the stall-fed condition and farmers would be more benefited using complete pellet feed compared to conventional grass or urea molasses straw (UMS) and concentrate based feeding system. No disease or clinical symptoms were observed in the animals during the experimental period, suggesting that pellet feeds are well accepted by the sheep and results in better growth rate.
\end{abstract}

Keywords: Growth, Native sheep, Pellet, Stall feeding, Total mixed ration

*Corresponding author: sadek_11@yahoo.com 


\section{INTRODUCTION}

Sheep is a vital small ruminant species which is widely distributed throughout the world and also considered as docile animals and famous for having capability of biannual lambing and multiple births (FAO, 2014; Bhuiyan, 2006). At present, the global sheep population stands at more than one billion head, with 19 per cent found in Asia and Africa (FAO, 2014). Worldwide sheep are used for producing meat, milk and wool. It is an essential source of income for the sheep farmers requiring minimum investment, care and management. In Bangladesh, sheep population is about 3.34 million, and ranks third in number after cattle and goat population, and issued primarily for meat production purpose (DLS, 2015). Though the number of animals is satisfactory, their performance is inferior. Sheep are mostly reared in the extensive system in Bangladesh (Sultana et al., 2011). Around $85 \%$ of the total is reared under low input system and the rest $15 \%$ is found under medium input system (BBS, 2000).

Currently, the livestock sector in Bangladesh produces only $30.18 \%$ total requirement of meat and the per capita meat consumption is still deficient (only 8.6 $\mathrm{kg}$ ) compared to developing countries $(42.1 \mathrm{~kg}$ ) and the world $(32.2 \mathrm{~kg}$ ) (Huque, 2012). To meet this huge gap, the meat production of the country must be increased many folds emphasizing sheep as a meat animal. Poor plane of nutrition is one of the major limiting factors in sheep production in Bangladesh has more than $90 \%$ of the feed consumed by the ruminants in Bangladesh are rice straw (Khan et al., 2009), which is characterized by high fiber and low protein, energy, mineral and vitamin contents which cannot meet even the maintenance requirements of animals. As a result, the digestibility and intake are low, which results in poor performances (Sultana et al., 2017). The productivity of sheep may be increased by improving nutrition through supplementation of concentrates or compound feed. Complete pellet feed is a good option in this regard to ensure the balanced nutrition for the sheep in intensive rearing system since pellet feeding gives nutrition to sheep in a balanced form. Pelleting of low-quality roughages and other products like wheat bran, molasses helps in increasing the palatability and digestibility of this feed with reducing feed wastage (Reddy and Eshwaraih, 1989; Reddy et al., 1990). Moreover, it plays a vital role in several physicochemical and organoleptic parameters of meat quality like proximal composition, the fatty acid profile, tenderness, and color (Retamal and Morales, 2014). Therefore, the present experiment was designed to develop a total mixed ration based complete pellet feed and evaluate its utilization for commercial sheep production under intensive or stall-fed condition.

\section{Materials and methods}

\section{Collection and processing of feedstuffs}

Rice straw and agro industry-based concentrate feed ingredients were purchased from the local sources. Rice straw was used as a roughage source with the agro industry-based concentrate mixture to formulate the basal total mix ration (TMR) for 
pelleting according to the nutrient requirement of goats. For the pelleting of feed, a small-scale pelleting machine was designed and fabricated locally. All the roughages were ground to $5 \mathrm{~mm}$ size using Hammer mill machine containing $5 \mathrm{~mm}$ size sieve.

\section{Preparation of Pellet}

$40 \%$ roughage (rice straw) and $60 \%$ concentrate (rice polish $50 \%$, maize crush 16 $\%$, soybean meal $20 \%$, molasses $10 \%$, salt $2 \%$, DCP $1 \%$, vitamin-mineral premix $0.5 \%$, pellet binder $0.5 \%$ ) were used for the formulation of complete pellet feed in locally fabricated simple extruder machine (Ahmed et al., 2008; Roy et al., 2010). Before passing it to the pelleting machine, $50 \%$ of water of the total mixture was added for better mixing. The prepared pellet was sun-dried and stored before sheep feeding. The approximate diameter of complete pellet was 4-6 mm.

\section{Chemical Composition of experimental diet}

Before the chemical analysis pellet and other feed samples of the experimental diets were dried and ground in a grinding mill through 2-mm and 1-mm sieve respectively. Crude protein $(\mathrm{CP})$ content of the experimental diet was determined using the automated Kjeldahl method (AOAC, 2019). Dry matter (DM) content of the feed was determined by drying the samples at $105^{\circ} \mathrm{C}$ overnight, while ash was measured by burning further at $500^{\circ} \mathrm{C}$ for 4 hours. The neutral detergent fiber (NDF) and acid detergent fiber (ADF) composition were analyzed using the method described by Goering and Van Soest (1970). The chemical composition (\%) of the pellet feed is given in Table 1 .

Table 1. Chemical composition (\%) of the experimental diets

\begin{tabular}{lccccc}
\hline Ingredients/feed & DM & Ash & CP & ADF & NDF \\
\hline Complete pellet feed & 91.70 & 14.29 & 13.40 & 32.24 & 51.56 \\
Oat fodder & 13.74 & 5.78 & 16.54 & 51.6 & 78.8 \\
UMS & 61.73 & 12.3 & 9.45 & 61.31 & 73.8 \\
Concentrated mixture & 88.55 & 5.93 & 18.65 & 9.98 & 35.81 \\
\hline
\end{tabular}

$\mathrm{DM}=$ Dry matter; $\mathrm{CP}=$ Crude protein; $\mathrm{ADF}=$ Acid detergent fiber, $\mathrm{NDF}=$ Neutral detergent fiber; UMS= Urea molasses straw

\section{Selection and management of sheep}

\section{On the research station}

The experiment was conducted at Bangladesh Livestock Research Institute (BLRI), Savar, about 24 kilometers northwest of the capital city of Bangladesh. For this study, 18 intact male Native Bengal lambs of the age of 4 to 5 months were selected. The lambs were divided into three treatment groups (having six animals in each group) by stratified randomization based on their average body weight. The control groups were fed ad libitum Oat grass $\left(\mathrm{T}_{1}\right)$, and ad libitum UMS $\left(\mathrm{T}_{2}\right)$ with concentrate supplementation (@1.5\% of body weight). The concentrate mixture contained $42 \%$ broken maize, $38 \%$ soybean meal, $17 \%$ wheat bran, $1 \%$ vitamin, 1 
$\%$ DCP and $1 \%$ salt. The treatment group $\left(\mathrm{T}_{3}\right)$ was fed ad libitum complete pellet feed for the intensive production of sheep. The animals were housed in individual pens on a plastic slated floor equipped with separate feeder and waterer. The sheep were dewormed at the onset of the experiment. The feed was offered two times daily ( 9 am and $4 \mathrm{pm}$ ) and orts were collected before morning feeding to know the feed intake. Animals were weighed weekly before morning feeding. The duration of the experiments was 90 days.

\section{On the farmers' level}

The experiment was conducted at Subornachar Upazila under Noakhali district of Bangladesh. Total 14 farmers were selected having at least one male lamb with 4 to 5 months of age. They were equally distributed into two treatment groups $\left(\mathrm{T}_{0}\right.$ and $\mathrm{T}_{1}$ ) having seven lambs in each group. In $\mathrm{T}_{0}$, lambs were reared under traditional semi-intensive system (allowed 8 hours grazing in fallow land, no or minimal concentrate supplementation and provided night shelter), while $T_{1}$ lambs were reared under stall feeding condition and fed complete pellet feed. The duration of the experiment was 90 days. Data from above two treatments $\left(T_{0}\right.$ and $\left.T_{1}\right)$ were compared with on-station pellet feeding data, designated as $\mathrm{T}_{2}$ obtained from the research station study.

\section{Metabolic trial}

Immediately after the growth trial in the research station; three animals from each of the dietary group were randomly selected for determining digestibility of the feeds and nutrients using the total collection method. Metabolic trays were placed under individual pens for the collection of feces and urine separately. The animals continued to be fed on the experimental diets. They were allowed three days to adjust before the start of the total collection of urine and feces for seven days. The feces of each of the animals were collected, weighed, and sampled (10\%), and kept in a freezer $\left(-20^{\circ} \mathrm{C}\right)$ for further analysis. The total urine of each of the animal was weighed, sampled $(10 \%)$, and kept in plastic containers containing $100 \mathrm{ml} 6 \mathrm{~N}$ $\mathrm{H}_{2} \mathrm{SO}_{4}$ to prevent ammonia loss. The containers were kept in a freezer. The samples of feed and refusals of the total collection period were mixed thoroughly, and a composite sample for each animal was taken for analysis of the chemical components

\section{Economics of feeding experimental pellets}

Cost of per kg pellet preparation, cost of per $\mathrm{kg}$ meat production and the return was calculated to know benefit to cost ratio (BCR) for pellet feeding. The cost of per $\mathrm{kg}$ pellet feed preparation was Bangladesh Taka (BDT) 20.14 according to the average market price of all ingredients used for pellet preparation (Table 2). To calculate the $\mathrm{BCR}$, selling price of per $\mathrm{kg}$ of meat was considered about BDT 600.00. The dressing percentage was assumed to be about $50 \%$, i.e. $1 \mathrm{~kg}$ live weight gain indicates $0.50 \mathrm{~kg}$ of meat and price is BDT 300.00. Total cost per $\mathrm{kg}$ of each 
experimental diet was calculated by taking into consideration procurement price of various feed ingredients used and processing cost. The prices of major ingredients were collected from Livestock and Poultry feed market in Savar, Dhaka, Bangladesh. On the basis of this cost, economics of feeding was calculated.

Table 2. Average price of feed ingredients available in study area and time

\begin{tabular}{lc}
\hline Name of the ingredients & Price in BDT/Kg \\
\hline Rice straw & 10 \\
Rice polish & 21 \\
Broken maize & 21 \\
Soybean meal & 38 \\
Wheat bran & 27 \\
Molasses & 22 \\
Salt & 17 \\
DCP & 65 \\
Vitamin mineral premix & 150 \\
Pellet binder & 300 \\
Urea & 16 \\
\hline
\end{tabular}

\section{Experimental design and statistical analysis}

The experiment was carried out in a completely randomized design (CRD) and the data were analyzed using the software IBMSPSS Statistics 20. The differences were tested by Duncan's Multiple range test (DMRT) test and significant differences were declared at $5 \%$ level of significance $(\mathrm{P}<0.05)$.

\section{Ethical standard and statement}

Principles of laboratory animal care (NIH publication No. 85-23, revised 1985) and specific applicable national laws were followed. All experiments have been examined and approved by the appropriate ethics committee.

\section{RESULTS AND DISCUSSION}

\section{Growth performances of sheep at the research station}

Table 3 shows the effect of complete pellet feed on the performances of growing sheep compared to conventional stall feeding. The DMI and daily weight gain was significantly $(\mathrm{p}<0.01)$ higher $(0.768 \mathrm{~kg}$ and $100.67 \mathrm{~g}$ respectively $)$ in Pellet fed group $\left(\mathrm{T}_{3}\right)$ compared to other groups $\left(0.415 \mathrm{~kg}\right.$ and $63.27 \mathrm{~g}$ respectively for $\mathrm{T}_{1}$ and $0.427 \mathrm{~kg}$ and $64.78 \mathrm{~g}$ respectively for $\mathrm{T}_{2}$ ). Higher DMI was observed in the pellet fed group indicating that grinding and pelleting increased the palatability and voluntary feed intake. A similar result was also found by Roy et al. (2010). Rashid et al. (2016) found significantly higher DMI by feeding roughage and concentrate in a compound pellet form to Black Bengal goats. In dairy cattle, Knaus et al. (1999) also 
reported the average daily forage DMI e increased from 12.8 to $18.6 \mathrm{~kg}$ when grassclover and whole plant maize were fed in the pellet form.

Table 3: Effect of complete pellet feed on the performances of growing sheep compared to conventional stall feeding.

\begin{tabular}{lllllc}
\hline Parameters & \multicolumn{3}{c}{ Treatments } & SEM & $\begin{array}{c}\text { Level of } \\
\text { sig. }\end{array}$ \\
\cline { 2 - 4 } & $\mathrm{T}_{1}$ & $\mathrm{~T}_{2}$ & $\mathrm{~T}_{3}$ & & NS \\
Initial weight (kg) & 10.69 & 11.01 & 10.80 & 0.325 & $*$ \\
Final weight (kg) & $16.38^{\mathrm{a}}$ & $16.84^{\mathrm{a}}$ & $19.86^{\mathrm{b}}$ & 0.639 & $* 6^{\mathrm{a}}$ \\
Weight gain (kg) & $5.694^{\mathrm{a}}$ & $5.83^{\mathrm{a}}$ & $9.06^{\mathrm{b}}$ & 0.485 & $* *$ \\
Weight gain/day (g) & $63.27^{\mathrm{a}}$ & $64.78^{\mathrm{a}}$ & $100.67^{\mathrm{b}}$ & 5.388 & $* *$ \\
DMI (kg) & $0.415^{\mathrm{a}}$ & $0.427^{\mathrm{a}}$ & $0.768^{\mathrm{b}}$ & 0.045 & $* *$ \\
DMI (\% body weight) & $3.07^{\mathrm{a}}$ & $3.21^{\mathrm{a}}$ & $5.13^{\mathrm{b}}$ & 0.261 & $* *$ \\
FCR & 7.11 & 6.87 & 7.39 & 0.201 & $\mathrm{NS}$ \\
Feed cost/kg gain (BDT) & 166.35 & 176.33 & 169.06 & 4.992 & $\mathrm{NS}$ \\
Total cost/kg gain (BDT) & 219.84 & 224.99 & 219.15 & 6.532 & $\mathrm{NS}$ \\
Meat price/kg (BDT) & 300.00 & 300.00 & 300.00 & 0.00 & $\mathrm{NS}$ \\
BCR & 1.37 & 1.33 & 1.37 & 0.037 & $\mathrm{NS}$ \\
\hline
\end{tabular}

$\mathrm{ab}=$ different superscript in the same raw differ significantly; $*=\mathrm{p}<0.05 ; * *=\mathrm{p}<0.01 ; \mathrm{T}_{1}=\mathrm{Ad}$ libitum oat grass + concentrate mixture @ $1.5 \%$ of body weight; $\mathrm{T}_{2}=$ Ad libitum UMS + concentrate mixture @ $1.5 \%$ of body weight; $\mathrm{T}_{3}=$ Ad libitum developed complete pellet feed

Daily weight gain was significantly higher $(\mathrm{p}<0.01)$ in Pellet fed group (T3) compared to other groups on conventional feeds. Rashid et al. (2016) found significantly higher $(\mathrm{p}<0.05)$ daily live weight gain in case of goats fed with compound pellet diet than the same amount of mash or grass and concentrate feed fed separately. No differences were observed for the feed cost per $\mathrm{kg}$ of weight gain and FCR among the groups.

Table 4 shows the nutrient digestibility of different treatment groups of sheep. The CP digestibility $(\%)$ was found significantly $(\mathrm{p}<0.05)$ high in $\mathrm{T}_{1}$ group (69.77) followed by $\mathrm{T}_{3}$ (54.75) and $\mathrm{T}_{2}$ (45.72), but the DM, OM, ADF and NDF did not differ significantly among the treatment groups. This may be due to the use of highquality green oat grass as a basal roughage source for $T_{1}$ group animals. Although the CP digestibility was low, the average daily gain was significantly higher in the $\mathrm{T}_{3}$ group, suggesting that pelleting enhanced the efficiency of utilization of feed. More or less similar results were found by the other researchers (Nicholson et al., 1996; Reddy and Reddy, 1999; Reddy et al., 2002). 
Table 4. Nutrient digestibility of feed (\%) fed by different treatment groups of sheep

\begin{tabular}{|c|c|c|c|c|c|}
\hline \multirow{2}{*}{ Parameter } & \multicolumn{3}{|c|}{ Treatment } & \multirow{2}{*}{ SEM } & \multirow{2}{*}{$\begin{array}{c}\text { Level of } \\
\text { Sig. }\end{array}$} \\
\hline & $\mathrm{T}_{1}$ & $\mathrm{~T}_{2}$ & $\mathrm{~T}_{3}$ & & \\
\hline DM digestibility & 63.89 & 56.02 & 60.60 & 2.529 & NS \\
\hline OM digestibility & 71.03 & 61.35 & 63.04 & 2.430 & NS \\
\hline CP digestibility & $69.77^{\mathrm{b}}$ & $45.72^{\mathrm{a}}$ & $54.75^{\mathrm{ab}}$ & 4.283 & $*$ \\
\hline ADF digestibility & 44.48 & 52.43 & 47.16 & 3.637 & NS \\
\hline NDF digestibility & 57.88 & 52.43 & 52.00 & 2.946 & NS \\
\hline
\end{tabular}

${ }^{\mathrm{ab}}=$ different superscript in the same row differ significant; $*=\mathrm{p}<0.05 ; \mathrm{T}_{1}=$ Ad libitum oats grass + concentrate mixture @ $1.5 \%$ of body weight; $\mathrm{T}_{2}=$ Ad libitum UMS + concentrate mixture @ $1.5 \%$ of body weight; $\mathrm{T}_{3}=$ Ad libitum developed complete pellet feed

No disease or clinical symptoms was observed during the experimental period due to feeding of rice straw-based complete pellet feed indicating that pellet feeding did not alter the normal rumen function of the animals and animal Physiology. Arable land for grazing sheep is decreasing day by day due to increasing population and urbanization. Therefore, farmers have to be encouraged to adopt stall feeding system for sheep farming using agro-industrial by-products based alternative feeds.

\section{On-farm performances of sheep fed complete pellet feed}

This study was conducted at Subarnachar Upazila under Noakhali district to know the performances of sheep fed complete pellet feed at farmer's household. Table 4 shows the on-farm performances of lambs fed on complete pellet feed. Performance data of the pellet fed group at on-farm state $\left(\mathrm{T}_{1}\right)$ was compared with on-station data of pellet fed group $\left(\mathrm{T}_{2}\right)$ while the performances of the traditional semi-intensive group $\left(\mathrm{T}_{0}\right)$ was considered as a control group. Similar DM intake was observed both for on-farm $\left(T_{1}\right)$ and on-station group $\left(T_{2}\right)$. Likewise, FCR, feed cost per kg weight gain and total cost (labour, feed cost and feed preparation) per kg weight gain did not differ between $T_{1}$ and $T_{2}$ groups. Results suggest that the sheep fed with the pellet feed performed evenly both for on-station and on-farm groups. In the traditional system of rearing $\left(\mathrm{T}_{0}\right)$ only $22.42 \mathrm{~g}$ daily weight gain was observed while feeding of complete pellet feed achieved $84.98 \mathrm{~g}$ and $100.67 \mathrm{~g}$ daily weight gain at on-farm $\left(\mathrm{T}_{1}\right)$ and on-station $\left(\mathrm{T}_{2}\right)$ conditions respectively. The results (Table 5) indicate that the daily weight gain increased significantly $(\mathrm{p}<0.01)$ about $4-5$ times incomplete pellet fed groups on-farm $\left(\mathrm{T}_{1}\right)$ and on-station $\left(\mathrm{T}_{2}\right)$ compared to the traditional system of rearing $\left(\mathrm{T}_{0}\right)$. Better (1.37) BCR was observed in the $\mathrm{T}_{2}$ group compared to the $T_{1}$ group (1.18) although, the figures did not differ significantly. $\mathrm{BCR}$ for both the on-farm and on-station feeding group was higher than 1, indicating that the farmers will be benefited by using complete pellet feed for the production of sheep. 
Table 5. Performances of sheep fed on complete pellet feed at the on-farm condition

\begin{tabular}{lllllc}
\hline Parameters & \multicolumn{3}{c}{ Treatments } & SEM & Level of sig. \\
\cline { 2 - 4 } & $\mathrm{T}_{0}$ & $\mathrm{~T}_{1}$ & $\mathrm{~T}_{2}$ & & \\
\hline Initial weight $(\mathrm{kg})$ & 9.25 & 9.85 & 10.78 & 0.741 & $\mathrm{NS}$ \\
Final weight $(\mathrm{kg})$ & $10.82^{\mathrm{a}}$ & $15.80^{\mathrm{b}}$ & $19.86^{\mathrm{b}}$ & 1.2497 & $* *$ \\
Body weight change (kg) & $1.57^{\mathrm{a}}$ & $5.95^{\mathrm{b}}$ & $9.08^{\mathrm{c}}$ & 0.783 & $* *$ \\
DMI (kg/day) & - & 0.73 & 0.77 & 0.025 & $\mathrm{NS}$ \\
FCR & - & 8.93 & 7.68 & 0.450 & $\mathrm{NS}$ \\
Daily weight gain (g) & $22.42^{\mathrm{a}}$ & $84.98^{\mathrm{b}}$ & $100.67^{\mathrm{b}}$ & 9.066 & $* *$ \\
Feed cost /kg gain (BDT) & - & 197.70 & 168.58 & 10.053 & $\mathrm{NS}$ \\
Total cost/kg weight gain & & 257.01 & 219.15 & 13.069 & $\mathrm{NS}$ \\
(BDT) & & 300.00 & 300.00 & 0.000 & $\mathrm{NS}$ \\
Meat price/kg (BDT) & & 1.18 & 1.37 & 0.069 & $\mathrm{NS}$ \\
BCR & & & & $\mathrm{P}$ \\
\hline
\end{tabular}

${ }^{\mathrm{ab}}=$ different superscript in the same row differ significantly; $*=\mathrm{P}<0.05 ; * *=\mathrm{P}<0.01 ; \mathrm{T}_{1}=$ pellet feeding group at on-farm condition; $\mathrm{T}_{2}=$ on-station data of pellet feeding group; $\mathrm{T}_{0}=$ traditional semi-intensive feeding group

No disease or clinical symptoms were observed during the experimental period due to using rice straw-based complete pellet feed indicating that pellet feeding did not alter the normal rumen function of the animals and animal Physiology. Both on-farm and on-station results confirm that straw based complete pellet feed could be an alternative ready to feed option for commercial sheep production under intensive or stall-fed conditions.

\section{CONCLUSION}

Complete pellet feeding in sheep was found to enhance dry matter intake, daily weight gain, improve feed efficiency and reduce the feed cost for sheep production. Thus, under the current situation of declining arable grazing lands, it could be expected that this technology of straw based completed feed pellets will help to increase sheep production under stall feeding conditions.

\section{Acknowledgement}

This research was funded by PIU-BARC, NATP-2 Project, Bangladesh Agricultural Research Council, Farmgate, Dhaka, Bangladesh, through CRG sub-projects.

\section{Conflict of interests}

There is no potential conflict of interest in this study, including in the preparation of the manuscripts and publications of this article. 


\section{REFERENCES}

Ahmed, S., Khan, M.J. and Talukder, M.A.I. (2008). Development of complete pellet feed and its utilization for intensive sheep production in Bangladesh. Proceeding of Annual Research Review workshop, 2008 held at Bangladesh Livestock research Institute, Savar, Dhaka-1341. Bangladesh.

AOAC. (2019). Official Methods of Analysis (21 $1^{\text {st }}$ edition). Association of Official Analytical Chemists, Washington, D.C., USA.

BBS. (2000).Bangladesh Bureau of Statistics. Planning Division, Ministry of Planning. Government of the People's Republic of Bangladesh, Dhaka, Bangladesh.

Bhuiyan, A.K.F.H. (2006). Livestock genetic resources in Bangladesh: Preservation and Management. International conference on livestock services, Chinese Academy of Agricultural Science (CAAS), Beijing, China.

DLS. (2015). Livestock Economy at a Glance 2015-16, Department of Livestock Services, Ministry of Fisheries and Livestock, Bangladesh.

FAO. (2014). Food and Agriculture Organization of the United Nations. Production year book.

Goering, H.K. and Van Soest, P.J. (1970). Forage fiber analysis (apparatus, reagents, procedures and some applications). Agrie. Handbook 379.ARS, USDA, Washington, DC.

Huque, K.S. (2012). Changes in and challenges of Bangladesh livestock. BLRI Newsletter 3. Bangladesh Livestock Research Institute, Dhaka, Bangladesh. Pp.1.

Khan, M.J., Peters, K.J. and Uddin, M.M. (2009). Feeding strategy for improving dairy cattle productivity in small holder farm in Bangladesh. Bangladesh Journal of Animal Science, 38 (1\&2):67-85.

Knaus, W., Luger, K., Zollitsch, W., Gufler, H., Gruber, L., Murauer, C. and Lettner, F. (1999). Effects of grass clover-pellets and whole plant maizepellets on the feed intake and performance of dairy cows. Animal Feed Science and Technology, 81:265-277.

Nicholson, J.W.G., McQueen, R.E., Allen, J.G. and Bush, R.S. (1996). Effect of mash or pelleted supplements containing crab meal on intake and weight gains of beef cattle. Canadian Journal of Animal Science, 76:95-103.

Rashid, M.A., Khan, M.J., Khandoker, M.A.M.Y. and Monir, M.M. (2016). Feeding different forms of ration including compound pellet and performance of growing Black Bengal goat. IOSR Journal of Agriculture and Veterinary Science, 9(5):01-08. 
Reddy, G.V.N. and Reddy, M.R. (1999). Effect of feeding extruded complete diet containing maize cobs in Ongole bull calves. Indian Journal of Animal Nutrition, 16:210-214.

Reddy, G.V.N., Reddy, J.K. and Nagalakshmi, D.(2002). Effect of expanderextruder processed complete diet containing sugarcane bagasse on growth and nutrient utilization in Ongole bull calves. Indian Journal of Animal Sciences, 72(5):406-409.

Reddy, G.V.N., Reddy, M.R. and Rao, A.M. (1990). Effect of particle size on physical characters and nutrient utilization of Prosopisjuliflora pods in sheep. Indian Journal of Animal Nutrition, 7 (2):123-126.

Reddy, V.R. and Eshwariah, M. (1989). Effect of graded replacement of fish meal with vegetable proteins in broiler starter rations. Indian Journal of Animal Nutrition, 6(2):166-168.

Retamal, J.R. and Morales, R. (2014). Influence of breed and feeding on the main quality characteristics of sheep carcass and meat. Chilean Journal of Agricultural Research, 74(4):516-519.

Roy, B.K., Ahmed, S., Sarker, N.R., Roy, A. and Singh, Y. (2010). The effect of feeding different roughages in pelleted diets on growth performance of Black Bengal Goats. Indian Veterinary Journal, 87:905-907.

Sultana, N., Hasan, N., Iqbal, N.A., Ershaduzzaman, M. and Talukdar, M.A.I. and Dey, S. (2011). Effect of intensive and semi-intensive feeding system on productive and reproductive performances of native sheep. Journal of Scientific Research, 3(3), 693-698.

Sultana, N., Rakib, M.R.H., Hossain, S.M.J., Ahmed, S., Ershaduzamman, M. and Talukder, M.A.I. (2017). Effect of Replacement of conventional concentrate in a rice straw diet by moringa foliage on lamb production performances. Journal of Experimental Agriculture International, 15(5):1-14. 